\title{
Impact of process parameters on refused derived fuel pellets
}

\author{
M. K. Iqbal ${ }^{1 *}$, A. Nadeem ${ }^{2}$ and M. T. Butt ${ }^{1}$ \\ ${ }^{1}$ PCSIR Laboratories Complex Lahore, Pakistan \\ ${ }^{2}$ GCW Baghbanpura Lahore, Pakistan
}

Received: 19 June 2018

Revised: 11 July 2018

Accepted: 03 December 2018

DOI: https://doi.org/10.3329/bjsir.v55i1.46734

\begin{abstract}
The objective of present study was to optimize the process conditions for the development of refused derived fuel (RDF) pellets from municipal solid waste (MSW) and biomass by using Response Surface Methodology (RSM). The three factors specifically moisture (20-45\%), preheating temperature $\left(50-120^{\circ} \mathrm{C}\right)$ and pressure $(500-1500 \mathrm{psi})$ were taken as center point. The experimental data of response variables were fitted into quadratic polynomial model using the multiple regression analysis and found it was statistically significant quadratic model and contour plot further revealed that moisture $(20 \%)$, preheating temperature $\left(120^{\circ} \mathrm{C}\right)$ and hydraulic pressure $(1000 \mathrm{psi})$ were the best conditions. Moreover bulk density and durability of pellets increased due to temperature and pressure but decrease with moisture. The bulk density (BD) moisture durability (DU) size diameter carbon hydrogen sulpher chloride ash fixed carbon HHV (High heating value) LHV (Low heating value) and ash metal were also evaluated.
\end{abstract}

Keywords: RDF; Moisture; Durability; Bulk density; RSM; temperature

\section{Introduction}

Pakistan currently facing severe energy shortfall due to high cost of energy fuels, continued depletion of natural resources and mismanagement. The way to overcome this crisis, usage of cheap and abundant renewable energy sources like biomass and municipal solid waste that entails substantial socioeconomic and environmental benefits (Bosmans et al., 2014).

It is very challenging to handle, transport and store; municipal solid waste (MSW) in its original form as a fuel due to high moisture contents (60-70\%), irregular shape, size and bulk density whereas biomass arean excellent energy source and reduced moisture from municipal solid waste turnin to refuse derived fuel (RDF) through palletization technology. RDF has the advantages of low moisture content, higher calorific value, high storage capacity due to its compact size, easy to be transported and uniform combustion characteristics.

Palletization technology recently promoted in developing countrieslike Pakistan as a technique to enhance the bulk density, shelf life and transportation. This technology compressed MSW in to compact shape without using binder or any additive under high pressure and temperature. MSW containing cellular material release lignin, which binds the smaller particles in to compact unit for efficient transport and longtime conservation.

There are two types of moulding machine for the development of RDF pellets. One type is dry moulding and other is extruder type. Each type has a basic structure of disk with holes pistonand dye length over diameter ratio and raw material moisture contents (20-30\%) for compressing in to RDF.

Garcia-Maraver et al. (2015) investigated the impact of palletization technology and material composition on the bulk density, hardness and other physical characteristics of RDF. Moreover in previous studies RDF development from various biomass; bagasse, rice husk, corn cob, cotton sticks, 
sewage and industrial sludge has been reported as an alternative energy source (Montero et al., 2014).

The properties of pellets depends upon various factors; feed stock, moisture contents, particle size, compression force, binding agent, pelletizer typeand other operational and environmental conditions. The physical and chemical properties of solid waste and biomass are very imperative to determine the combustion behavior and efficiency of RDF pellets. The ultimate, proximate analysisdesignated the gross calorific and net calorific value whereas bulk density defined the particle heating rate and thermal efficiency.

The operating conditionslike preheating temperature, feedstock moisture and pressure impact on pellet development. These operating conditions should be optimized because individual condition cannot produce the best quality RDF pellets.

Numerous authors had shepherded single-factor optimization to assess the best process conditions for pelleting. It is unreliable and may lead to misinterpretation of results and it does not illustrate the interactive effects among the variables and guarantee the determination of optimal conditions. At the moment, statistics-based experimental design (RSM) has been reported in the literature, which is time saving and lessen the error in determining the interactive consequence of process parameters (Iqbal et al., 2015).

Response Surface Methodology (RSM) iscommonly applied because it illustrates the impact of independent variables alone or in combination in smooth way to help in achieving the goal.Many researchers have successfully used these designs for developing response surface models to investigate how the moisture contents of raw material, densification pressure and temperatureeffect hardness bulk density and durability of pellets. Numerous scientists also conducted their research work on densification of herbaceous and woody biomass using pellet mills and screw/piston press Zafari and Kianmehr, 2014) but still there is no extensive research work has been conducted regarding the optimization of RDF pelletsfrom MSW and biomass at these operating conditions. Therefore it is essential to investigate the influence of RSM conditions on physical properties of RDF pellets; bulk density and durability under hydraulic press.In addition another objective was to characterize thephysical andchemical properties of RDF pellets.

\section{Materials and methods}

\section{Feed Stock}

Municipal Solid Waste (MSW) was collected from Muslim Town Lahore and haulted to RDF Plant at PCSIR
Laboratories Complex Lahore, Pakistan. It was segregated manually after conning and quartering process to get the appropriate composition of $\mathrm{MSW}$ for RDF formation having the high gross calorific value. The physical composition of MSW revealed a Food Waste $22.32 \pm$ 1.23; Wood, Grass and Leaves 21.10 \pm 1.09 ; Paper (Include Tetra Pack) 6.6 \pm 0.98 ; Leather and Rubber $2.04 \pm 0.05$; Cloth 30.46 \pm 3.54; Plastic (Polyethene) 9.28 \pm 2.35 ; Dust, Stone and Ceramics $2.1 \pm 0.03$; Metals $1.09 \pm 0.01$; Glass $1.86 \pm 1.1$; Others $3.2 \pm 0.56$ (Table-I).

Table I. Physical characterization of MSW

\begin{tabular}{|c|c|c|}
\hline Type of Waste & Percentage Composition & Units \\
\hline Food Waste & $22.32 \pm 1.23$ & $\%$ \\
\hline Wood, Grass and Leaves & $21.10 \pm 1.09$ & $\%$ \\
\hline Paper (Include Tetra Pack) & $6.6 \pm 0.98$ & $\%$ \\
\hline Leather and Rubber & $2.04 \pm 0.05$ & $\%$ \\
\hline Cloth & $30.46 \pm 3.54$ & $\%$ \\
\hline Plastic (Polythene) & $9.28 \quad \pm 2.35$ & $\%$ \\
\hline Dust, Stone and Ceramics & \pm 0.03 & $\%$ \\
\hline Metals & $1.09 \pm 0.01$ & $\%$ \\
\hline Glass & $1.86 \pm 1.1$ & $\%$ \\
\hline Others & \pm 0.56 & $\%$ \\
\hline
\end{tabular}

\pm : S.D of three replicates

The sawdust was purchased from local market and determined surface moisture at $38^{\circ} \mathrm{C}$ for the period of $24 \mathrm{~h}$ (ASTM-2007). The air dried sawdust sample was further analyzed for particle size distribution with apparatus (Retsch); using standard sieves $2 \mathrm{~mm}, 1 \mathrm{~mm}, 500 \mu \mathrm{m}$, $250 \mu \mathrm{m}, 125 \mu \mathrm{m}, 63 \mu \mathrm{mby}$ taking $500 \mathrm{~g}$ sample of sawdust for the period of 30 mints at constant speed of $60 \mathrm{rpm}$. Sieved $1 \mathrm{~mm}$ saw dust was used to adjust the moisture for pellet formation as per RSM design.

\section{Experimental design and RDF pellets formation by RSM}

The optimization of process parameters required for the development RDF pellets from feed stock (MSW and biomass) were accomplished by using the statistical designexperiments. The moisture, pressure and preheating temperature parameters were optimized for BD and DU of pellets by using Box-Behnken design. It consist of three levels; Low (-1), medium (0) and high (+1).In present study the independent variables (pressure, preheating temperature and moisture) were optimized to get the best combination for the formation of RDF pellets, because the variation in moisture and preheating temperature; impacts on binding 
capacity, BD and DU of pellets. The preset ranges of independent variables were preheating temperature $\left(50-120^{\circ} \mathrm{C}\right)$, pressure $(500-1500 \mathrm{psi})$ and feed stock moisture $(20-45 \%)$. The moisture adjustment by sawdust $(1 \mathrm{~mm})$ and preheating temperature of feedstock was maintainedin all pelleting experiment as per experimental design. The present experiment was employed to fit the second order polynomial model, which indicates the required experiments trials: 15 . All the experiments were carried out in triplicates according to design matrix, which was based on number of variables. The independent variable and the mathematical relationship of response $Y_{1}$, $\mathrm{Y}_{2}$ of these variables were approximated by quadratic polynomial equations for hardness optimization.

$Y_{1}=\beta_{0}+\beta_{1} X_{1}+\beta_{2} X_{2}+\beta_{3} X_{3}+\beta_{11} X_{1}^{2}+\beta_{22} X_{2}^{2}+\beta_{33} X_{3}^{2}+\beta_{12} X_{1} X_{2}+\beta$ ${ }_{13} X_{1} X_{3}+\beta_{23} X_{2} X_{3}$

$Y_{1}$ is the predicted response, $\beta_{0}$ is the constant, $\beta_{1}, \beta_{2}, \beta_{3}$ are the linear co-efficient, $\beta_{11}, \beta_{22}, b \beta_{33}$ are the quadratic coefficient and $\beta_{12}, \beta 13, \quad \beta 23$ are the cross-product coefficients.

The optimum values of the selected variables were obtained by solving the regression equation. Analysis of Variance (ANOVA) was also carried out to define statistical significance of independent variables with dependent variables for pellet formation. RSM model develop the contour plot to understand the interactive effect of process variables on pellet $\mathrm{BD} /$ durability. The statistical software design (version: 16) was used for experimental design, data analysis and graph plotting.

\section{Description of die drawing and pellet formation}

In order to study the process of pellet formation two dieswere fabricated having schematic hollow M.S cylinder (3) of length $304.8 \mathrm{~mm}$ and outer diameter $200 \mathrm{~mm}$. It has $175 \mathrm{~mm}$ and $191 \mathrm{~mm}$ internal diameter from the upper and lower side respectively (Fig.1). The two degree taper was provided from the upper side in the die cylinder to eject the pellets effortlessly by applying hydraulic pressure with plunger. One die was provided a M.S. cylinder (3) and base plate (4) to release the air packets and reduce the gaps between particles; produced during RDF pellet formation. The predetermined ratio of feedstock; 500 gmwas filled manually in to die cylinder to make single pellets in both dies. The iron rod plunger (5) topwaspressed with Hydraulic press (60 ton) at specific pressure as experimental designto compress the charged feedstock. The pellets were ejected by removing the base plate and again put the hydraulic pressure with plunger to remove the pellets from die.The pellets were stored in sealed plastic bags at controlled lab conditions(Temp: $25^{\circ} \mathrm{C}, \mathrm{H}: 35-40 \%$ ) to examine physical and chemical properties of pellets.

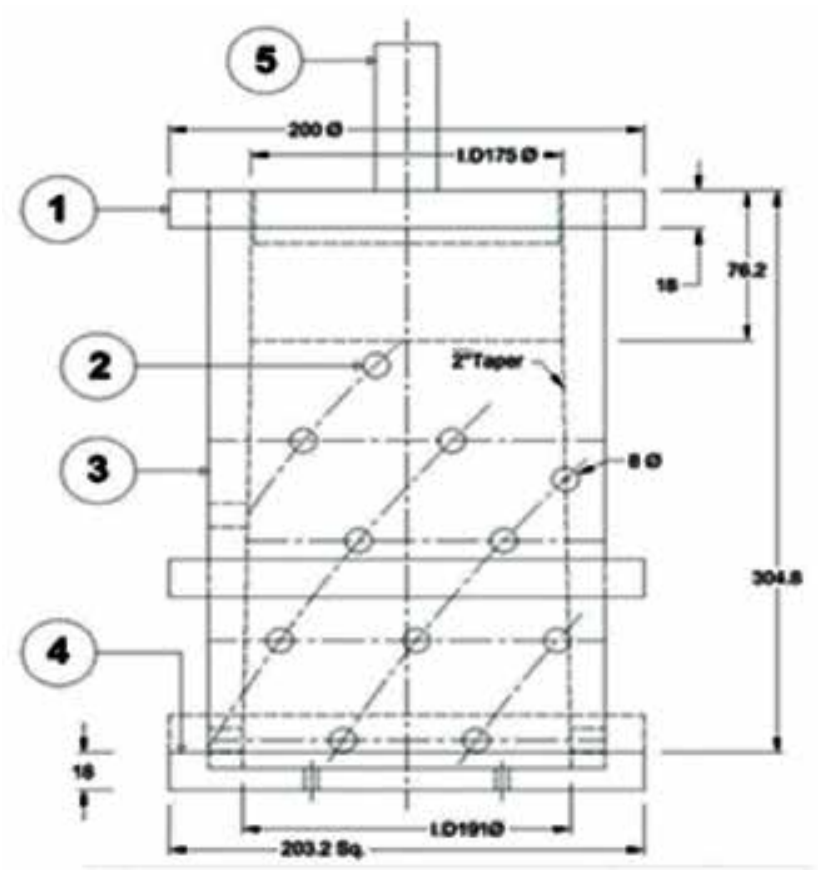

Fig. 1. Drawing of Pelleting die

\section{Characteristics of RDF pellets}

\section{Size of RDF pellets}

There were 25 pellets samples were selected from different trials to determine the length and diameter by using the Vernier Caliper and their average results were reported with S.D.

\section{Proximate ultimate and chlorine contents analysis}

The samples of feedstock and each trial were milled, homogenize and determined the moisture $\left(104^{\circ} \mathrm{C}\right)$, ash $\left(550^{\circ} \mathrm{C}\right)$ and volatile matter $\left(950^{\circ} \mathrm{C}\right)$ as per prescribed method of ASTM-2007.

The CHNS (Elementar) was used to determine carbon, hydrogen, nitrogen and sulpher by using the oxidation reduction tubes of CHNS and chlorine contents were determined during gross calorific value (Parr-6200) estimation by adding the $10 \%$ solution of $\mathrm{Ca}(\mathrm{OH})_{2}$ for dissolving the soluble chlorine contents and proceeded further as perASTM-2007. The same procedure was adopted for feed stock and other materials. 


\section{Metal analysis}

The metal analysis ( $\mathrm{Si}, \mathrm{Al}, \mathrm{Fe}, \mathrm{Ca}, \mathrm{Mg}, \mathrm{Na}, \mathrm{K}, \mathrm{Ti}, \mathrm{SO}_{3} \& \mathrm{P}_{2} \mathrm{O}_{5}$ ) of sawdust, MSW and RDF pellets was conducted through high tech instrument ICP by acid digestion.

\section{Low and higher heating value}

The calorific value or higher heating values of feed stock and pellets were determined by using the Bomb Calorimeter (Parr-6200) three times and average results were reported with standard deviation. The lower heating value was also determined as per ASTM-2007, the hydrogen contents were taken from ultimate analysis.

\section{Bulk density}

The bulk density was determined by measuring the volume, mass and dimension according to ASTM-2007 procedures respectively. The pellets were randomly selected from each trail and reported the average results with standard deviation.

\section{Durability}

The pellet samples were sieved to remove the fines before analysis of durability. The pellets were $(500 \mathrm{~g})$ subjected separately in perforated tumbler for the period of 5 minutes to collide at $50 \mathrm{rpm}$ with each other and with hard surface of the tumbler. After completing the cycle of 5 minutes the pellets were collected separately; reweight and calculate the difference in percentage that depict the durability of pellets (ASABE,2007).

\section{Hardness}

The hardness of RDF pellets was analysed with single press unit with hemisphere end rods. The compressive force was applied to the center of cylindrical pellets after placing horizontal on steel plate. The tester speed was $2 \mathrm{~mm} / \mathrm{min}$ and recorded the maximum force when the pellet break/fracture. The Meyer hardness was calculated by following equation (Lam et al., 2011).

Where $\mathrm{h}$ is the indentation depth $(\mathrm{mm}) ; \mathrm{F}$ is fracturing force in " $\mathrm{N}$ " and $\mathrm{D}$ is the diameter of rod in $\mathrm{mm}$.

\section{Statistical analysis}

Each physico-chemical characteristics of feed stock and RDF pellets of various trials were analyzed three times, and their results were reported as an average along with standard deviation.

\section{Results and discussion}

\section{Characteristics of feed stock and RDF pellets}

The results from the analysis of MSW, sawdust and RDF are summarized in Table-II which shows the average values of determined parameters. The visual observation showed the variation in the size of various pellets in some trials. It was confirmed by talking the observation with calibrated Vernier Caliper and found that pellets have nearly same diameter because these were produced under the same conditions, however some difference has been observed in length of some trials.

The moisture contents of MSW (50.67\%), saw dust (5.8\%) and $\mathrm{RDF}\left(8.49 \%\right.$ dried at $70^{\circ} \mathrm{C}$ in oven for $\left.6 \mathrm{~h}\right)$ revealed that these values were similar to other woody pellets but moisture content of MSW was $88.55 \%$ more than sawdust. It was reduced by the addition of sawdust as per experimental design. It has impact on the net calorific value, combustion efficiency and temperature of combustion. Regarding the ash contents exhibited the differences in their results due to varied nature of MSW composition and increasing of ash lower the heating value of fuel and implies the risk for sintering and dust emission (Zamorano et al., 2011). The biomass residues are characterized of higher volatile matter comprises the efficiency to ignite easily and burn more effectively. Sawdust enhanced the volatile matter of RDF pellets $45.55 \%$ more than MSW due to variety of woods in sawdust.

RDF contains different elements $(\mathrm{C}, \mathrm{H}, \mathrm{N}, \mathrm{S}, \mathrm{O})$ but the main element was carbon, with value roundabout $50 \%$, explain the low heating value. In addition the sulpher $21.7 \%$ lower than MSW root to the formation of harmful gasses. Moreover other hydrogen element value was lower than $7 \%$; contributes significantly to the overall heating value. It helps to delineate the quantity of air required for complete combustion, composition of flue gasses and heat of combustion. These results are coherent to Garcia-Maraver et al. (2015) and close to other values reported in literature for RDF.

The HHV of RDF samples were within the range from the literature consulted. These values showed alteration due to variation in moisture of RDF samples as per experimental design. It was increased in RDF than MSW due to the presence of greater concentration of lignin in sawdust. Biomass lignin has low degree of oxidation and considerably high combustion heat impacts on the HHV and LHV. The biomass and MSW contain high degree of mineral oxides causing the low melting of ash are fouling, slagging and corrosion of heat transfer surfaces. The concentration of 
Table II. Proximate, ultimate and metal analysis of feed stock and RDF

\begin{tabular}{|c|c|c|c|c|c|}
\hline \multicolumn{2}{|l|}{ Parameters } & ASTM Method \# & MSW & Saw Dust & RDF \\
\hline \multicolumn{2}{|c|}{ Air Dry Moisture (\%) } & E-949 & $5.3 \pm 1.04$ & $1.2 \pm 0.01$ & $3.65 \pm 1.02$ \\
\hline \multicolumn{2}{|c|}{ Inherent Moisture (\%) } & E-949 & $47.91 \pm 4.32$ & $4.67 \pm 0.45$ & $5.030 .23 \pm$ \\
\hline Total Moisture & $(\%)$ & E-949 & $50.67 \pm 3.21$ & $5.8 \pm 0.32$ & $8.491 .1 \pm$ \\
\hline Ash contents & $(\%)$ & E-830 & $13.43 \pm 1.32$ & $11.56 \pm 2.34$ & $15.43 \pm 2.12$ \\
\hline Volatile Matter & $r \quad(\%)$ & E-897 & $35.56 \pm 3.21$ & $70.23 \pm 6.02$ & $65.32 \pm 4.67$ \\
\hline Fixed Carbon & $(\%)$ & -- & $3.1 \pm 0.2$ & $7.74 \pm 1.3$ & $14.22 \pm 2.01$ \\
\hline HHV & (Btu/lb) & E-711 & $3498.32 \pm 13.43$ & $7645.67 \pm 32.56$ & $7022 \pm 25.6$ \\
\hline LHV & $(\mathrm{Btu} / \mathrm{lb})$ & E-711 & $2979.15 \pm 4.32$ & $7586.33 \pm 67.98$ & $6934.85 \pm 13.23$ \\
\hline Hydrogen & $(\%)$ & D-5373 & $5.6 \pm 0.01$ & $0.64 \pm 0.0$ & $6.56 \pm 1.09$ \\
\hline Carbon & $(\%)$ & D-5373 & $47.30 \pm 1.2$ & $58.32 \pm 0.01$ & $49.54 \pm 3.56$ \\
\hline Sulpher & $(\%)$ & D-5373 & $0.23 \pm 0.01$ & $0.12 \pm 0.00$ & $0.18 \pm 0.01$ \\
\hline $\mathrm{SiO}_{2}$ & (Wt.\%) & D-6349 & $33.40 \pm 1.01$ & $86.601 \pm 1.1$ & $41 . .32 \pm 4.21$ \\
\hline $\mathrm{Al}_{2} \mathrm{O}_{3}$ & $(\mathrm{Wt} . \%)$ & D-6349 & $15.49 \pm 2.45$ & $0.185 \pm 0.023$ & $1.34 \pm 0.08$ \\
\hline $\mathrm{Fe}_{2} \mathrm{O}_{3}$ & $(\mathrm{Wt} . \%)$ & D-6349 & $11.09 \pm 1.32$ & $0.597 \pm 0.02$ & $0.97 \pm 0.0$ \\
\hline $\mathrm{CaO}$ & (Wt.\%) & D-6349 & $21.32 \pm 2.45$ & $5.893 \pm 0.54$ & $13.09 \pm 1.02$ \\
\hline $\mathrm{MgO}$ & $(\mathrm{Wt} . \%)$ & D-6349 & $1.01 \pm 0.00$ & $2.084 \pm 0.45$ & $0.93 \pm 0.02$ \\
\hline $\mathrm{Na}_{2} \mathrm{O}$ & (Wt. \%) & D-6349 & $14.87 \pm 0.03$ & $1.256 \pm 0.43$ & $6.54 \pm 1.12$ \\
\hline $\mathrm{K}_{2} \mathrm{O}$ & (Wt. \%) & D-6349 & $0.61 \pm 0.00$ & $1.388 \pm 0.54$ & $0.32 \pm 0.022$ \\
\hline $\mathrm{TiO}_{2}$ & $(\mathrm{Wt} . \%)$ & D-6349 & $0.9 \pm 0.003$ & $0.080 \pm 0.002$ & $0.0 \pm 0.0$ \\
\hline $\mathrm{SO}_{3}$ & $(\mathrm{Wt} . \%)$ & D-6349 & $0.0 \pm 0.0$ & $1.697 \pm 0.05$ & $0.11 \pm 0.01$ \\
\hline $\mathrm{P}_{2} \mathrm{O}_{5}$ & $(\mathrm{Wt} . \%)$ & D-6349 & $1.32 \pm 0.006$ & $0.203 \pm 0.021$ & $1.02 \pm 0.01$ \\
\hline Chlorine (total & ) $\quad(\%)$ & E-776 & $0.03 \pm 0.01$ & $0.03 \pm 0.01$ & $0.04 \pm 0.001$ \\
\hline
\end{tabular}

$\pm:$ SD of three replicates (SD: Standard Deviation)

mineral oxides varies according to type of waste. The same tendency was found in all the samples regarding chlorine.

\section{Impact of moisture on RDF pellets quality}

The data was obtained for bulk density (BD) and durability (DU) of RDF pellets from the experiment carried out under $\mathrm{RSM}$ at moisture $(20-45 \%)$, temperature $\left(50-120^{\circ} \mathrm{C}\right)$ and pressure (500-1500 psi). It revealed that final moisture contents of the RDF pellets were dependent upon the feedstock moisture. Less feedstock moisture (20\%), high temperature $\left(120^{\circ} \mathrm{C}\right)$ and pressure $(1000 \mathrm{psi})$ demonstrated BD \& DU $932 \mathrm{~g} / \mathrm{kg}$ and $90.9 \%$ respectively whereas higher feedstock moisture $(45 \%)$ high temperature $\left(120^{\circ} \mathrm{C}\right)$ and pressure (1000 psi) resulted the BD and DU $824 \mathrm{~g} / \mathrm{kg}$ and
$79.76 \%$ respectively (Table-III). BD decrease initially with the moisture contents increasing in some trials whereas those trials having low moisture with high temperature and pressure produced the good quality pellets. Trial (13) reflected that the $\mathrm{BD}$ and DU were 74.9 and $71.3 \%$ more respectively than trial (8). It was due to less moisture contents in trial (13) than trial (8) but have the different temperature and pressure range also. These results are consistent with Jiang et al (2014) which showed that BD and DU of densified product have peak at optimized moisture contents (20\%). All other trials also defined the BD and DU as per experimental conditions but there was no remarkable results were achieved. In the pelleting process moisture has the key importance for binding. It acts as binder and lubricant due to hydrogen bonding and Vander wall forces available in 
Table III. Box-Behnken design matrix along with experimental and predicated values for bulk density and durability optimization

\begin{tabular}{llllcccc}
\hline Std & $\begin{array}{c}\text { Moisture } \\
(\%)\end{array}$ & $\begin{array}{c}\text { Temperature } \\
\left({ }^{\circ} \mathrm{C}\right)\end{array}$ & $\begin{array}{c}\text { Pressure } \\
(\text { Psi })\end{array}$ & Experimental & Predicated & Experimental & Predicated \\
\hline 1 & 45 & 120 & 1000 & 824 & 820.5 & 79.76 & 80.43 \\
2 & 20 & 50 & 1000 & 505 & 508.5 & 49.45 & 48.78 \\
3 & 20 & 85 & 1500 & 782 & 766.75 & 75 & 75.37 \\
4 & 20 & 85 & 500 & 304 & 337.25 & 37.8 & 40.21 \\
5 & 32.5 & 120 & 1500 & 879 & 915.75 & 89 & 90.74 \\
6 & 45 & 50 & 1000 & 332 & 353.5 & 40.67 & 42.78 \\
7 & 32.5 & 85 & 1000 & 569 & 569 & 63 & 63.00 \\
8 & 32.5 & 50 & 500 & 234 & 197.25 & 26.09 & 24.35 \\
9 & 32.5 & 85 & 1000 & 569 & 569.0 & 63.0 & 63.00 \\
10 & 32.5 & 85 & 1000 & 569 & 569.0 & 63.0 & 63.00 \\
11 & 45 & 85 & 1500 & 532 & 498.75 & 63.0 & 60.59 \\
12 & 32.5 & 50 & 1500 & 387 & 398.75 & 45.0 & 45.31 \\
13 & 20 & 120 & 1000 & 932 & 910.5 & 90.9 & 88.79 \\
14 & 45 & 85 & 500 & 345 & 360.25 & 41.0 & 40.63 \\
15 & 32.5 & 120 & 500 & 561 & 549.25 & 56.9 & 56.59 \\
\hline
\end{tabular}

biomass water molecules. It makes thin film of water around particles would exhibit bond via capillary action between particles. This water molecule induces variety of physical and chemical changes like denature of protein, softening of biomass and gelatinization of starch upon heating. Consequently only a limited quantity of water is required for softening of lignin to produce high quality of RDF pellets. Mani et al. (2004) conducted the study on four biomass grinds of wheat, barely straw, corn stover and switch grass at different moisture indicated that a lower feedstock moisture contents produced pellets with high densities as compared to those with higher feed stock moisture contents. These results are coherent to present study.

The present study results were not promising at moisture contents greater than $20 \%$ because moisture trapped within the particles may prevent complete flattering and release of natural binders. One important observation was the spiral holes on the die also hinder during compression of feedstock. These holes released pressure along with some quantity of water contain in the feed stock. It causes a relative sliding between the particles may be the major cause for pellet fracture or low BD and DU in some trials (data not shown). The hardness of pellets demonstrated the same trend at moisture contents of $20 \%$. Therefore the appropriate moisture contents for biomass and MSW pelleting was $20 \%$.

Impact of pressure and preheating temperature on $R D F$ quality

In palletization pressure is a significant factor for pellet formation. It promotes adhesion by enhancing molecular contacts between adjacent molecules in biomass matter. The higher the pressure the closer the solid particles resulting the higher BD and DU (Jiang, et al., 2014). Durability (DU) indicated the ability of pellets to withstand physical disintegration. It can also be illustrated as the ability of pellets not to lose weight during storage and transportation (Tumuluru, 2014). Preheating temperature, feed stock moisture, binder, particle size and densification pressure are the key factors effect on densified product DU, BD and hardness. In this study pressure applied was 500-1500psi by hydraulic press on the feedstock available in the die during pellet formation. In general trend DU and BD increased with the increase of pressure in all trials. High pressure reduces the moisture contents in the feedstock by the release of water and compact the MSW and biomass feedstock effectively and produces high BD and DU comprising pellets. Trial (13) and (1) have the same pressure and temperature but trial (13) has 
$11.6 \%, 12.25 \%$ more $\mathrm{BD}$ and $\mathrm{DU}$ than trial (1) due to differences in moisture. The least DU and BD was examined in trial (8) due to less preheating temperature and pressure because less pressure not shoved the feed stock material to release the water molecules; ultimately water slides the particles and not made stronger bond for good quality BD and DU pellets. Recent literature supports the present finding that the pellet DU and BD increased exponentially with the applied pressure during densification (Hoover et al.,2014).

Process variables are moisture, pressure and preheating temperature impact on pelleting process. Among these preheating temperature has the key role during densification; affect both chemical composition and mechanical processing for improving the quality of pellets (Tumuluru, 2014). It also reduced the energy demand per kilogram of biomass pellets formed for different end user application (Bhattacharya 1993). Preheating in presence of high moisture plays a significant impact to soften the natural binders like starch, lignin and protein in biomass prior to palletization and assist to produce pellets of high $\mathrm{BD}$, hardness and DU. This phenomenon was observed in present study. The moisture as per RSM condition was $20 \%$, pressure 1000 psi and preheating temperature $120^{\circ} \mathrm{C}$, these factors correlate each other during this process and produced best quality of pellets. Those trials have low preheating temperature their lignin and protein did not act as binder and pellets of low BD and DU. It was due to only short ranged forces like hydrogen bonding and Van der Waals forces. In addition the high moisture was reduced by preheating and natural binders becomes soften which enhanced the pellet formation in trial 1, 13 and 5 whereas all other trials did not demonstrate the significant results. The protein and lignin are the main softener for co-palletization of MSW and biomass and their glass transition temperature ranged from $50-113^{\circ} \mathrm{C}$ for different biomass materials. Kaliyan and Morey (2009) reported in their study that increasing of moisture from $10-20 \%$ reduces glass transition temperature up to $70^{\circ} \mathrm{C}$. According to Serrano et al. (2011) the highest DU was achieved at moisture content value of $19-23 \%$ along with preheating temperature. The present study results corroborate the same observation for hardness.

Table IV. Estimated regression coefficient for bulk density and durability

\begin{tabular}{|c|c|c|c|c|c|}
\hline & Term & Coef & SECoef & $\mathrm{T}$ & $\mathrm{P}$ \\
\hline \multirow[t]{11}{*}{ Bulk Density } & Constant & -90.1812 & 255.382 & -0.0353 & 0.738 \\
\hline & Moisture & -7.8051 & 9.157 & -0.852 & 0.433 \\
\hline & Temperature & -4.5561 & 3.150 & -1.446 & 0.208 \\
\hline & Pressure & 1.3069 & 0.201 & 6.513 & 0.001 \\
\hline & Moisture* Moisture & 0.1752 & 0.121 & 1.448 & 0.207 \\
\hline & Temperature* Temperature & 0.0423 & 0.015 & 2.743 & 0.041 \\
\hline & Pressure * Pressure & -0.0004 & 0.00 & -5.585 & 0.003 \\
\hline & Moisture* Temperature & 0.0371 & 0.042 & 0.894 & 0.412 \\
\hline & Moisture* Pressure & -0.0116 & 0.003 & -4.004 & 0.010 \\
\hline & Temperature $*$ Pressure & 0.0024 & 0.001 & 2.270 & 0.072 \\
\hline & & $\mathrm{R}^{2}=99.0 \%$ & & $\mathrm{R}^{2}(\mathrm{Adj})=97.21 \%$ & \\
\hline \multirow[t]{11}{*}{ Durability } & Constant & -35.4707 & 16.6147 & -2.135 & 0.086 \\
\hline & Moisture & -0.0113 & 0.5958 & -0.019 & 0.986 \\
\hline & Temperature & 0.2546 & 0.2049 & 1.242 & 0.269 \\
\hline & Pressure & 0.1103 & 0.0131 & 8.448 & 0.00 \\
\hline & Moisture* Moisture & 0.0069 & 0.0079 & 0.873 & 0.423 \\
\hline & Temperature* Temperature & 0.0009 & 0.0010 & 0.911 & 0.404 \\
\hline & Pressure $*$ Pressure & -0.000 & 0.000 & -08.025 & 0.000 \\
\hline & Moisture* Temperature & -0.0013 & 0.0027 & -0.499 & 0.639 \\
\hline & Moisture* Pressure & -0.0006 & 0.0002 & -3.215 & 0.024 \\
\hline & Temperature $*$ Pressure & 0.0002 & 0.0001 & 2.790 & 0.038 \\
\hline & & $\mathrm{R}^{2}=99.46 \%$ & & $\mathrm{R}^{2}(\operatorname{adj})=98.48 \%$ & \\
\hline
\end{tabular}




\section{Optimization of bulk density and durability}

Box-Behnken design under response surface methodology was used to determine the interactive impact of feedstock moisture, applied pressure by hydraulic press and preheating temperature to achieve appropriate combination for the development of RDF having high bulk density and durability because these parameters have strategic role to evaluate the properties of RDF developed from biomass and MSW.

The design matrixes of these variables (feed stock moisture, applied pressure and preheating temperature) for bulk density and durability of RDF pellets were in coded units are presented in table-IV along with predicted and experimental values of each factor. The predicted values for BD and DU were calculated by using the quadratic model fitting techniques with software design. The statistical model was developed by putting the multiple regression analysis on experimental values (BD and DU of Pellets) obtained during development of RDF from biomass and MSW.

The statistical model was analyzed by $\mathrm{F}$ test and the analysis of variance (ANOVA) for the response surface quadratic model is accessible in Table- $\mathrm{V}$. The model $\mathrm{F}$ test value of 55.21 and 101.88 indicates that the model is highly significant for both bulk density and durability optimization respectively. The $\mathrm{P}$ value were also less than 0.05 presented that the result values of BD and DU of pellets can be fitted well by a second order response surface plot. These values indicated that the model is exceedingly significant. The present study results were in line with Iqbal et al. (2015) reported that the $\mathrm{P}$ values also less than 0.05 indicate the model was significant in their study.

The lak of fit values are another proof that all the model coefficients namely moisture, preheating temperature, applied pressure, moisture ${ }^{2}$, temperature ${ }^{2}$, pressure $^{2}$, moisture and pressure, moisture and temperature, pressure and temperature are all these significant coefficient for BD and DU of RDF pellets. The goodness of the model was analyzed by determining the regression coefficient $\mathrm{R}^{2}$ and by adjusted $\mathrm{R}^{2}$ (multiple correlation coefficients $\mathrm{R}$ ). The value of determination coefficient $\mathrm{R}^{2}$ for $\mathrm{BD}$ and $\mathrm{DU}$ optimization $99 \%$ and $99.46 \%$ respectively indicated that only 1 and $0.54 \%$ were not explained by the model respectively.

Table V. Analysis of variance for bulk density and durability

\begin{tabular}{llllllll}
\hline & Source & Df & Seq.SS & Adi.SS & Adj.MS & F & P-value \\
\hline Bulk Density & Regression & 9 & 656140 & 656140 & 72904.5 & 55.21 & 0.00 \\
& Linear & 3 & 568905 & 69893 & 23297.8 & 17.64 & 0.00 \\
& Square & 3 & 58203 & 58203 & 19400.9 & 14.69 & 0.00 \\
& Interaction & 3 & 29033 & 29033 & 9677.6 & 7.33 & 0.028 \\
& Residual Error & 5 & 6602 & 6602 & 1320.5 & & \\
& Lack of Fit & 3 & 6602 & 6602 & 2200.8 & & \\
& Pure Error & 2 & 0 & 0 & 0.0 & & \\
& Total & 14 & 662743 & & & & \\
& & & & & & & \\
& Regression & 9 & 5124.62 & 5124.62 & 569.402 & 101.88 & 0.00 \\
& Linear & 3 & 4638.09 & 415.80 & 138.600 & 24.80 & 0.00 \\
& Square & 3 & 383.88 & 383.88 & 127.960 & 22.89 & 0.00 \\
& Interaction & 3 & 102.65 & 102.65 & 34.215 & 6.12 & 0.040 \\
& Residual Error & 5 & 27.95 & 27.95 & 5.589 & & \\
& Lack of Fit & 3 & 27.95 & 27.95 & 9.315 & & \\
& Pure Error & 2 & 0.00 & 0.00 & 0.00 & & \\
& Total & 14 & 5152.56 & & & &
\end{tabular}


The adjusted coefficient $\left(\right.$ Adj. $\left.\mathrm{R}^{2}=97.21 \%\right)(\mathrm{BD})$ and $98.48 \%$ (DU) were high, depicted the significance and goodness of the experimental work closer the values of adjusted $\mathrm{R}^{2}$ to 1 , and directs the better correlation between experimental and predicted values. The predicted $\mathrm{R}^{2}$ for DU was $98.48 \%$ is reasonable agreement with adjusted $\mathrm{R}^{2}$ (98.46\%) between experimental and predicted values for DU optimization. In addition the same observation was found for BD in present study.

The graph generated by model to understand the interaction between optimization parameters for RDF formation from biomass and MSW. The moisture is the key factor for pellet formation, concentration more than 20\%; is obstacles for good pellet formation and release of water from feed stock also slide the material on each other. In addition the preheating temperaturereduces the moisture and releases the binding agents; enhanced the DU and BD of RDF pellets. It helps to bind the feedstock with other particles. The application of pressure by hydraulic press or any other machine reduces the water contents and made closeness between particles and produce the pellets having high BD and DU.

The shape of contour plots (elliptical, circular) presented that whether the interrelation between these parameters is significant or not. The circular contour plots presented that the interaction between factors is also highly significant. The effect of moisture with temperature exhibited the inversely proportional relation for DU and BD. Moreover the same trend was found for the parameters moisture and pressure (Fig. 2) It supports the scientific angle the application of maximum pressure reduces the spaces between particles and releases the water from feedstock; enhanced the BD and DU of RDF pellets. In addition the intense color of contour plot is directly proportional to concentration of BD and DU means as contour plot color light, the $\mathrm{BD}$ and $\mathrm{DU}$ also showed declined in percentage.

By solving the equation 1 and 2 for both BD and DU using the software, the optimum values for pellet formation were moisture $(20 \%)$, applied pressure (1000psi) and temperature $\left(120^{\circ} \mathrm{C}\right)$ are the optimized parameters for development of RDF from MSW and biomass. The predicted values for BD and DU were 910.5 and $88.79 \%$ respectively.

\section{Validation of model}

Various trials were conducted during optimization of RDF pellets formation from MSW and biomass. The optimum process conditions; moisture $(20 \%)$, preheating temperature $\left(120^{\circ} \mathrm{C}\right)$ and pressure $(1000 \mathrm{psi})$ were used for the development of RDF from MSW and biomass. The results obtained as the BD and DU of RDF pellets was 910.5 $\mathrm{kg} / \mathrm{m}^{3}$ and $88.79 \%$ respectively. These results were observed better than conventional process during pellet formation.

\section{Conclusion}

The results obtained from this investigation indicated that it is possible to pellet high moisture MSW feedstock with manipulation of process variables like moisture, preheating temperature and applied pressure. The feedstock moisture content $20 \%$, preheating temperature $\left(120^{\circ} \mathrm{C}\right)$ and pressure (1000 psi) have reduced the final moisture of pellet up to $12 \%$ and other characteristics like BD and DU were $910.5 \mathrm{~kg} / \mathrm{m}^{3}$ and $88.79 \%$ respectively. Response surface model developed for quality attributes of RDF pellets process variables have

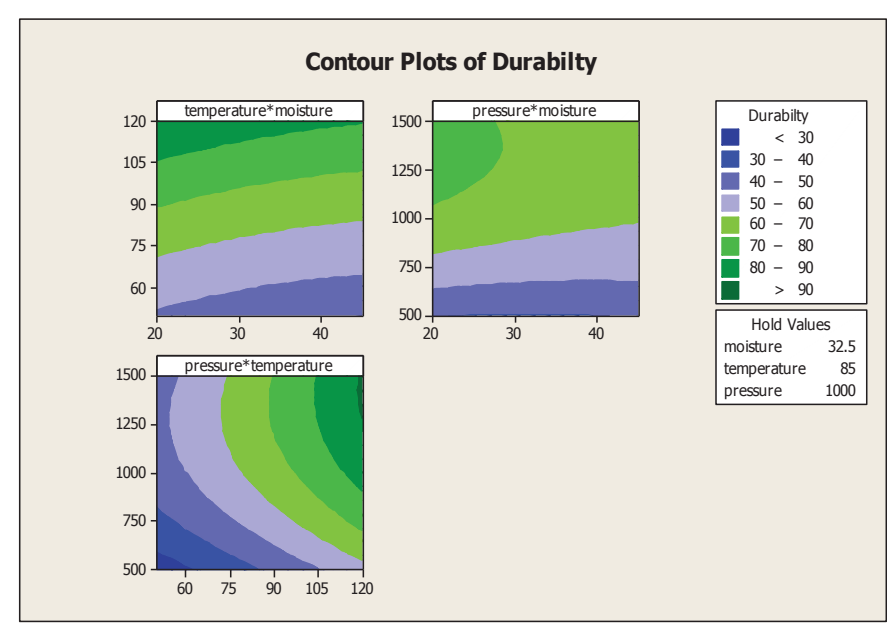

$\mathrm{a}$

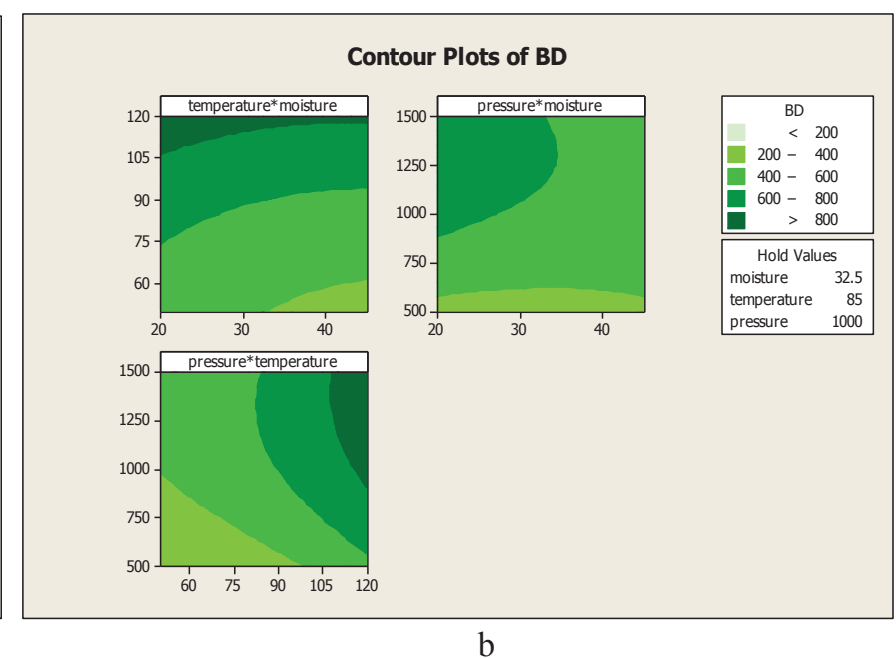

b

Fig. 2. Three dimensional plots (a) durability optimization (b) bulk density (BD) optimization 
efficiently described the process with coefficient of determination values of $>99.0$. Moreover co-palletization of MSW and biomass could be an alternative fuel technique for developing countries like Pakistan.

\section{References}

ASABE Standards S269.4. (2007), Cubes, pellets, and crumbles definitions and methods for determining density, durability and moisture content, St. Joseph, Michigan, U.S.A.

Bhattacharya SC (1993), State-of-the-art of utilizing residues and other types of biomass as an energy source, RERIC Int. J. Energy 15: 1-21.

Bosmans A, Dobbelaere CD and Helsen L (2014), Pyrolysis characteristics of excavated waste material processed into refuse derived fuel, Fuel. 122: 198-205. DOI: org/10.1016/j.fuel.2014.01.019

Garcia-Maraver A, Rodriguez ML, Serrano-Bernardo F, Diaz LF, Zamoranoa M (2015), Factors affecting the quality of pellets made from residual biomass of olive trees, Fuel Process. Technol. 129: 1-7.

Hoover AN, Tumuluru JS, Teymouri F, Moore J and Gresham $\mathrm{G}$ (2014), Effect of pelleting process variables on physical properties and sugar yields of ammonia fiber expansion pretreated corn Stover, Bioresour Technol. 164:128-135. DOI: org/10.1016/j. biortech. 2014. 02.005

Iqbal MK, Nadeem A, Sherazi F and Khan RA (2015), Optimization of process parameters for kitchen waste composting by response surface methodology, Int. J. of Environ. Sci \& Technol. 12: 1759-1768.

Jiang L, Liang J, Yuan X, Li H, Li C, Xiao Z, Huang H, Wang $\mathrm{H}$ and Zeng G (2014), Co-palletization of sewage sludge and biomass: The density and hardness of pellet, Bioresour Technol. 166: 435-443.
Kaliyan N and Morey R (2009), Factors affecting strength and durability of densified biomass product, Biomass and Bioengineer. 33: 337-359. DOI: org/10.1016/ j.biombioe. 2008.08 .005

Lam PS, Shahab Sokhansanj S, Bi X, Lim CJ and Melin S (2011), Energy input and quality of pellets made from steam-exploded douglas Fir (pseudotsugdmenziesu), Ener Fuels. 25: 1521-1528.

Mani S, Tabil LG and Sokhansanj S (2004), Evaluation of compaction equations applied to four biomass species, Can Biosyst Eng. 46: 3.55-3.61.

Montero I, Miranda MT, Sepúlveda FJ, Arranz JI, Trinidad M $\mathrm{J}$ and Rojas CV (2014), Analysis of Pelletizing of Granulometric Separation Powder from Cork Industries, Materi. 7: 6686-6700. DOI: org/10.3390/ ma7096686

Serrano C, Monedero E, Laupuerta M and Portero H (2011), Effect of moisture content, particle size and pine addition on quality parameters of barley straw pellets, Fuel Process Technol. 92: 699-706.

Tumuluru JS (2014), Effect of process variables on the density and durability of the pellets made from high moisture corn stover, Biosyst Eng. 119: 44-57. DOI: 10.1016/j.biosystemseng.2013.11.012

Zafari A and Kianmehr MH (2014), Factors affecting mechanical properties of biomass pellet from compost,Environ Technol. 35:478-86.

Zamorano M, Popov V, Rodríguez ML and García-Maraver A ( 2011), Comparative study of quality properties of pelletized agricultural and forestry lopping residues, Renew Ener. 36: 3133-3140. 